\title{
A study to evaluate importance of length from tip of olecranon to the tip of little finger in pre-operative assessment of $K$-nail in fracture shaft of femur in a tertiary care hospital of Bareilly district
}

\author{
Gaurav Singh $^{1}$, Ajit Singh ${ }^{1}$, Deepak Upadhyay ${ }^{2} *$
}

\begin{abstract}
${ }^{1}$ Department of Orthopedics, ${ }^{2}$ Department of Community Medicine, Rohilkhand Medical College and Hospital, Bareilly, Uttar Pradesh, India
\end{abstract}

Received: 05 February 2016

Revised: 08 February 2016

Accepted: 17 March 2016

\section{*Correspondence:}

Dr. Deepak Upadhyay,

E-mail: dr.deepakupadhyay@gmail.com

Copyright: (C) the author(s), publisher and licensee Medip Academy. This is an open-access article distributed under the terms of the Creative Commons Attribution Non-Commercial License, which permits unrestricted non-commercial use, distribution, and reproduction in any medium, provided the original work is properly cited.

\begin{abstract}
Background: The magnitude of incidence of femoral shaft fracture is approximately 15-20 fractures per 1,00,000 person years. Most commonly intramedullary nailing is preferred for adult femoral shaft fracture. The objective of this study was to assess the intra-medullary femoral nail length in adults by various methods in fracture shaft of femur and to access correlation between these lengths.

Methods: Study was conducted on 100 adult healthy volunteers including 41 males and 59 females attending the orthopaedic O.P.D of a tertiary medical college in North India. The length from tip of olecranon to the tip of little finger and the length from tip of the greater trochanter to the upper pole of patella of the same side were measured using a measuring tape on a couch.

Results: Analysis showed that the mean length from tip of olecranon to the tip of little finger and the length from tip of the greater trochanter to the upper pole of patella of the same side were 42.175 (SD, 2.0641) and 42.093 (SD, 2.0846) respectively. The mean difference between these two measurements was 0.083 (95\% CI, 0.020 to 0.145 ). The significant correlation was found between these 2 lengths i.e. 0.987 by Pearson co-relation (95\% CI, 0.977 to 0.994) $(\mathrm{p}<0.001)$. Age, sex and body mass index did not affect this correlation.

Conclusions: The length from the tip of the olecranon to the tip of the little finger correlated with the femoral length and is more convenient to perform and can also be used when the patient has sustained bilateral fractures of femur.
\end{abstract}

Keywords: Bone nails, Femoral fractures, Forearm, Fracture fixation, Intramedullary

\section{INTRODUCTION}

The magnitude of incidence of femoral shaft fracture is approximately 15-20 fractures per 1,00,000 person years. Most commonly intramedullary nailing is preferred for adult femoral shaft fracture. Length from the tip of the greater trochanter to the proximal pole of the patella on the contralateral side can also be used, but may be inaccurate. Length of femoral nail can be measured by various methods. X-ray of the normal thigh and a measured nail strapped to it can determine the proper pre- operative length of the nail. But, this is inconvenient, cost ineffective and unnecessary exposure to radiations also occur with this method. Accurate assessment can also be done by measuring from the greater trochanter to the superior pole of patella. Though this technique may cause inconvenience to patient while measuring injured part. Pre-operative assessment more easily can be done by measuring the length from the tip of the olecranon process to the tip of the little finger and is convenient. 
Therefore, the aim of this study was to analyze the means of these lengths and to see any differences and relation between this lengths. ${ }^{1-5}$

\section{METHODS}

The present study was conducted on healthy adults of age $>20$ years coming to the orthopedics OPD of a tertiary medical college in North India for any complaints. Study period was 2 weeks including OPD of all units. Persons who had past history of fracture of limb, congenital deformity, limb length discrepancies, and any pathology of bones, joints and limbs were excluded from this study. Prior ethical clearance from Institutional ethical committee was obtained before starting study.

Informed verbal consent was obtained from each participant. Length from the tip of the greater trochanter to the proximal pole of the patella and the length from the tip of the olecranon process to the tip of the little finger were measured using a measuring tape. The length from tip of the olecranon to the tip of the little finger was measured by flexing the elbow at $90^{\circ}$ with wrist and fingers in a neutral position. Greater trochanter became more prominent when thigh was slightly flexed and adducted and then the length from tip of the greater trochanter to the proximal pole of patella over outer aspect of thigh was measured in centimeters. Pearson correlation coefficient was used to measure the association between the 2 measurements. Statistically significance was considered at $95 \%$ confidence interval. An effect of sex and BMI on the correlation between the forearm plus little finger length and the femoral length was assessed using the correlation analysis, the independent t-test, and the analysis of variance, respectively.

\section{RESULTS}

Total 100 adults participated in the study. Out of these, 59 participants were females and 41 participants were males. Mean age of participants was 47.76. Out of 100 participants, 27 were under-weight (BMI $<18.5 \mathrm{~kg} / \mathrm{m}^{2}$ ), 54 were of normal weight $\left(\right.$ BMI $\left.=18.5-25 \mathrm{~kg} / \mathrm{m}^{2}\right), 15$ were overweight $\left(\mathrm{BMI}=25.1-29.9 \mathrm{~kg} / \mathrm{m}^{2}\right)$, and 4 were obese (BMI, $\geq 30 \mathrm{~kg} / \mathrm{m}^{2}$ ) (Table 1$)$.

Table 1: Demographic variables of participants.

\begin{tabular}{|ll|}
\hline Variables \\
\hline Sex \\
\hline Male & $41(41 \%)$ \\
\hline Female & $59(59 \%)$ \\
\hline BMI & \\
\hline Underweight & $27(27 \%)$ \\
\hline Normal & $54(54 \%)$ \\
\hline Overweight & $15(15 \%)$ \\
\hline Obese & $4(4 \%)$ \\
\hline Mean age (in Years) & 47.76 \\
\hline
\end{tabular}

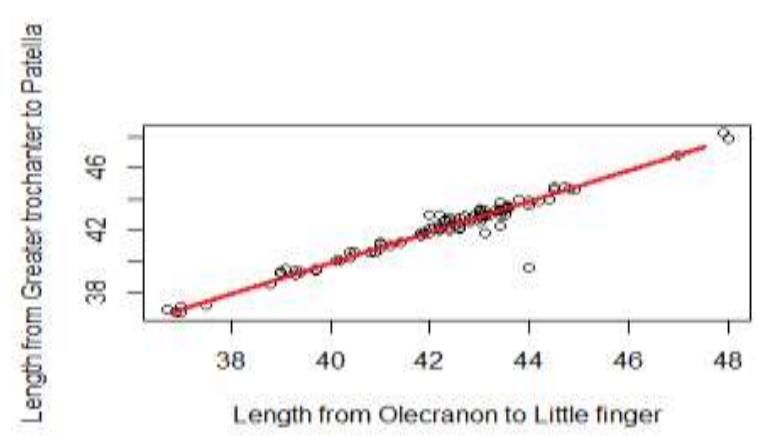

Figure 1: Scatter graph showing strong linear correlation between the Forearm plus little finger length and the femoral length.

The mean length from tip of olecranon to the tip of little finger and the length from tip of the greater trochanter to the upper pole of patella of the same side were 42.175 (SD, 2.0641) and 42.093 (SD, 2.0846) respectively (table 2).the mean difference between these two measurements was 0.083 (95\% CI, 0.020 to 0.145 ).

Table 2: Correlation between length from tip of olecranon to the tip of little finger and the length from tip of the greater trochanter to the upper pole of patella.

\begin{tabular}{|c|c|c|c|c|}
\hline Length & Mean \pm SD & Mean difference & Correlation coefficient & P value \\
\hline Olecranon to tip of the little finger & $42.175 \pm 2.0641$ & \multirow{2}{*}{$\begin{array}{l}0.083 \\
(95 \% \text { CI, } 0.020-0.145)\end{array}$} & \multirow{2}{*}{$\begin{array}{l}0.987 \\
(95 \% \text { CI, } 0.977-0.994)\end{array}$} & \multirow[b]{2}{*}{$\mathrm{p}<0.001$} \\
\hline $\begin{array}{l}\text { Greater trochanter to upper pole of } \\
\text { patella }\end{array}$ & $42.093 \pm 2.0846$ & & & \\
\hline
\end{tabular}

Significant correlation was found between these 2 lengths i.e. 0.987 by person co-relation $(95 \%$ ci, 0.977 to 0.994 ) $(\mathrm{p}<0.001)$, student's t test, table 2, Figure 1). Out of all participants, body mass index did not affect this correlation.
Both the sex showed high correlation between these length i.e. among males $\mathrm{r}=0.991$, among females $r=0.985$ and statistical analysis showed no effect of sex on correlation coefficient (Table 3 ). 
Table 3: Effect of sex, BMI and age on correlation coefficient between length from tip of olecranon to the tip of little finger and the length from tip of the greater trochanter to the upper pole of patella.

\begin{tabular}{|lll|}
\hline Variable & \multicolumn{2}{c|}{ Analysis } \\
\hline Sex & $\mathrm{Z}=1.22$ & $\mathrm{p}$ value $=0.222$ \\
\hline BMI & $\mathrm{F}=-3.48$ & $\mathrm{p}$ value $=0.323$ \\
\hline Age & $\mathrm{r}=0.21$ & $\mathrm{p}$ value $=0.07$ \\
\hline
\end{tabular}

\section{DISCUSSION}

$85 \%$ of the femoral shaft fractures are caused by motor vehicle accidents, $11 \%$ occur from fall and $6 \%$ are caused by gunshot injuries. Hey Groves, introduced intramedullary fixation for fracture shaft of femur. Femoral length restoration is one of the main treatment goals for femoral shaft fractures. Longer nails may protrude to the proximal femur causing movement restriction and bursitis whereas nails shorter in length may result in instability or stress fracture at distal tip., ${ }^{2,6,7}$

Standard femoral nail length measurement is done by the contralateral femoral length. The use of the forearm length as a reference has been reported. In clinical practice it can be easily used and applied. In this study, the correlation between the 2 measurements was 0.987 $(\mathrm{p}<0.001)$, and was not affected by sex, and BMI, age. ${ }^{2,4,8}$

\section{CONCLUSION}

In clinical practice, the length from tip of the olecranon to the tip of the little finger correlated with length from tip of the greater trochanter to the proximal pole of patella and is more convenient and can be simply performed and can also be used when patient has bilateral fractures of femur.
Funding: No funding sources

Conflict of interest: None declared

Ethical approval: The study was approved by the institutional ethics committee

\section{REFERENCES}

1. Hadlund R, Lindgren U. Epidemiology of diaphyseal femoral fractures. Acta Orthop. Scand. 1986;57:423-7.

2. Nork SE. Femoral shaft fracture. In: Rockwood and Green's fractures in adults. Bucholz RW, Heckman JD, Tornetta P, editors. Vol 1. Lippincott Williams and Wilkins; 2009:1655-1712.

3. Karakas HM, Harma A. Estimating femoral nail length in bilateral comminuted fractures using fibular and femoral head referencing. Injury 2007;38;984-7.

4. Lakhey S, Pradhan RL, Bishwakarma M, Pradhan S, Pradhanaga S, Pandey BK, et al. Pre-operative assessment of K-nail length in fracture shaft of femur. Kathmandu Univ Med J (KUMJ). 2006;4(3):316-8.

5. Taylor JC. Fractures of lower extremity. Campbell's Operative Orthopaedics Vol 2. Eighth edition. Edited by Crenshaw AH. Mosby Year Book, Missouri USA; 1992:863.

6. Epps $\mathrm{CH}$. Complications in orthopaedics surgery, Third edition, J.B. Lippincott Company; Philadelphia; 1994.

7. Hey Groves EW. On modern methods of treating fractures. Wright, Bristol; 1916.

8. Nazir A, Roy S, Mathur K, Alazzawi S. Estimation of femoral length for intramedullary nail using forearm as reference. J Bone Joint Surg $\mathrm{Br}$. 2009;91(1):37.

Cite this article as: Singh $\mathrm{G}$, Singh A, Upadhyay D, Singh K. A study to evaluate importance of length from tip of olecranon to the tip of little finger in pre-operative assessment of K-nail in fracture shaft of femur in a tertiary care hospital of Bareilly district. Int Surg J 2016;3:751-3. 